\title{
Oordrag van energie in nielineêre elektriese netwerke - 'n moderne beskouing van drywing
}

\author{
A. S. de Beer en J. D. van Wyk \\ Laboratorium vir Energie, Fakulteit Ingenieurswese, \\ RAU, Posbus 524, Johannesburg 2000
}

Omlang 2 Jamuarie 1991; anm'aar 2 Mei 1991

\section{UITTREKSEL}

Netwerke vir elektriese energieverspreiding bevat baie nielinêेe netwerkelemente in onsettingstoerusting, belasting en druwingselektroniese mutators. Dit veroorsaak vervorning van spannings en strome. Verskillende bydraes ten opsigle van 'n algemene drywingsteorie vir nielinềe netwerke word vir die bepaling van drywingskonponente gë̈valueer. 'n Nuwe teoretiese voorstel vir die bepaling van dryingskomponente, wat ook komponente soos verstrooide stroom insluit, word uiteengesit. Die toepassing van hierdie teorie in die stuar van vervormingskompensators in kragnetwerke word in beginsel alangedui.

\section{ABSTRACT}

\section{Energy transfer in nonlinear electrical networks - a modern perception of electrical power}

Networks for electric power distribution contain many nonlinear elements in conversion equipment, loads and power electronic converters. This leads to distorted currents and voltages in the network. Several contributions regarding a general power theory for nonlinear networks are evaluated for determining the different power components. A new theoretical proposal for determining these components, including the concept of scattered current is discussed. The application of this theory to the control of distortion compensators in power networks is discussed in principle.

\section{SIMBOLELYS}

$\mathrm{D}_{\mathrm{B}} \quad$ = vervormingsdrywing volgens Budean $\mathrm{u}^{2}$

$\mathrm{D}_{\mathrm{E}} \quad=$ deaktiewe drywing volgens Enslin ${ }^{1}$

$\mathrm{D}_{\mathrm{g}} \quad=$ nieharmoniese drywingskomponent

$\mathrm{D}_{\mathrm{s}} \quad=$ verstrooide drywingskomponent

$\mathrm{G}_{\mathrm{c}}=$ ekwivalente konduktansie

$\mathrm{i}(\mathrm{t})=$ stroomlunksie

$\mathrm{i}_{4}(\mathrm{t})=$ aktiewe stroomkomponent

$\mathrm{i}_{\mathrm{d}}(\mathrm{t})=$ deaktiewe stroomkomponent

$i_{1}(t)=$ fiktiewe stroomkomponent

$\mathrm{i}_{y}(\mathrm{t})=$ nieharmoniese of gegenereerde stroomkomponent

$\mathrm{i}_{\mathrm{r}}(\mathrm{t})=$ reaktiewe stroomkomponent

$\mathrm{i}_{\mathrm{s}}(\mathrm{t})=$ verstrooide stroomkomponent

$\mathrm{I}=$ effektiewe stroomwaarde

$\mathrm{I}_{\mathrm{a}}=$ effektiewe waarde van $\mathrm{i}_{\mathrm{u}}(\mathrm{t})$

$\mathrm{I}_{\mathrm{g}}=$ effektiewe waarde van $\mathrm{i}_{\mathrm{g}}(\mathrm{t})$

$\mathrm{I}_{\mathrm{m}} \quad=$ effektiewe reële of komplekse harmoniese stroomwaarde
$\mathrm{I}_{\mathrm{o}} \quad=$ gemiddelde stroomwaarde (gelykstroomkomponent)

$\mathrm{I}_{\mathrm{r}} \quad=$ effektiewe waarde $\operatorname{van} \mathrm{i}_{\mathrm{r}}(\mathrm{t})$

$\overline{\mathrm{I}}^{*} \quad$ komplekse toegevoegde stroomfasor

$\mathrm{j} \quad=、-1$ of indeksgetal

$\mathrm{k}=$ indeksgetal

$\mathrm{m}$ = indeksgetal (harmonieke in stroom)

$\mathrm{n} \quad=$ indeksgetal (harmonieke in spanning)

$\mathrm{P} \quad=$ aktiewe drywing

$\mathrm{q} \quad=$ lading

$\mathrm{Q} \quad=$ reaktiewe drywing

$\mathrm{Q}_{\mathrm{B}} \quad=$ reaktiewe drywing volgens Budeanu²

$Q_{E} \quad=$ reaktiewe drywing volgens Enslin ${ }^{1}$

$\mathrm{Q}_{\mathrm{r}} \quad=$ reaktiewe drywingskomponent (volgens Czarnecki?)

$\mathrm{R}_{\mathrm{tII}}(\tau)=$ kruiskorrelasie tussen stroom en spanning

$\hat{\mathrm{R}}_{\mathrm{ui}}(\tau)=$ piekwaarde $\operatorname{van} \mathrm{R}_{\mathrm{ui}}(\tau)$

$\mathrm{S} \quad=$ skyn- of beladingsdrywing

$\overline{\mathrm{S}} \quad=$ skyn- of beladingsdrywing (fasor) 
$\mathrm{t}=\mathrm{tyd}$

$\mathrm{T}=$ periode

$\mathrm{u}(\mathrm{t})=$ spanningsfunksie

$\mathrm{U}=$ effektiewe spanningswaarde

$\mathrm{U}_{\mathrm{n}} \quad$ = effektiewe reële of komplekse harmoniese spanningswaarde

$\mathrm{U}_{\mathrm{o}} \quad=$ gemiddelde spanningswaarde

$\overline{\mathrm{U}}=$ spanningsfasor

$\mathrm{w}=$ energie

$\alpha_{\mathrm{n}} \quad=$ harmoniese fasehoek in spanning

$\beta_{\mathrm{m}}=$ harmoniese fasehoek in stroom

$\beta_{\mathrm{n}}=$ harmoniese susseptansie

$\gamma_{n}^{\prime}=$ harmoniese konduktansie

$\lambda=$ arbeidsfaktor

$\Lambda_{\mathrm{n}}=$ komplekse harmoniese lasadmittansie

$\omega=$ hoekfrekwensie

\section{INLEIDING}

Drywingsoordrag in elektriese kragnetwerke is bykans nooit volledig effektief nie, weens vervorming en ossillasies in stelsels en laste. Hierdie verskynsel is te wyte aan die reaktiewe eienskappe van byvoorbeeld elektriese masjiene en transformators of nielineêre eienskappe van byvoorbeeld drywingselektroniese mutators. Om effektiewe drywingsoordrag te verseker, moet hierdie negatiewe effekte teengewerk word deur kompensasie van die vervorming met behulp van passiewe en aktiewe toerusting. Hierdie artikel handel oor sekere van die verskillende teoretiese strominge in die bepaling van drywing en drywingskomponente, asook die effek van hierdie analise op die doeltreffendheid van kompensasie.

Die klassieke benadering, die benadering van $\mathrm{Bu}$ deanu ${ }^{2}$ en Nowomiejski, ${ }^{3}$ asook die tydvlakvoorstellings van Fryze ${ }^{5}$ en Enslin ${ }^{1}$ word bespreek. Die beperkinge van hierdie teorieë om met behulp van 'n reaktiewe kompensator (dit wil sê wat bestaan uit kapasitore, induktore, filters of geskakelde energiestoorelemente) die maksimum energic-oordrag of arbeidsfaktor te behaal, word ook aangetoon.

in Nuwe teorie volgens Czarnecki ${ }^{7}$ word bespreek. Hierdie teorie werp meer lig op die bepaling van die maksimum hoeveelhede drywing wat met reaktiewe kompensators gekompenseer kan word, terwyl dit ook meer spesifiek na die verskillende oorsake van drywingsk omponente verwys wat negatief op netto energie-oordrag inwerk.

\section{KLASSIEKE TEORIE}

Elektriese drywingsteorie is klassiek slegs vir stelsels gedefinieer waar sowel die stroom as spanning sinusvormig en van 'n enkele frekwensie is. In so 'n stelsel word die skyndrywing $(\overline{\mathrm{S}})$ gedefinieer as:

$$
\overline{\mathrm{S}}=\overline{\mathrm{U}} \cdot \overline{\mathrm{I}}^{*}
$$

waar $\bar{U}$ die spanningsfasor en $\overline{I^{*}}$ die komplekse toegevoegde van die stroomfasor verteenwoordig. Hierdie produk gee aanleiding tot 'n komplekse drywingshoeveetheid:

$$
\overline{\mathrm{S}}=\mathbf{P}+\mathrm{jQ} .
$$

Klassiek bestaan skyndrywing dus uit 'n reële gedeelte, naamlik die aktiewe drywing $(P)$, en ' $n$ imaginêre of reak tiewe gedeelte $(\mathrm{Q})$. $\mathrm{P}$ word geassosieer met die netto energie-oordrag vanaf die bron na die las, terwyl $Q$ na die ossillerende gedeelte van die drywing verwys. Die klassieke teorie is besonder beperk en ongeskik vir algemene drywingsanalise, aangesien die fasorvoorstelling nie vir bofrekwensiespanning- of stroomharmonieke voorsiening maak nie. Dit is slegs geldig vir stelsels waarin sowel die spanning en die stroom enkelvoudigharmoniese funksies van tyd is.

\section{AKTIEWE EN BELADINGSDRYWING}

In die vakgebied van drywingsanalise is daar twee hoeveelhede wat algemeen en per definisie aanvaar word, naamlik: aktiewe drywing $(P)$ en beladings- of skyndrywing (S). Hoewel dit hier in die tyddomeinvorm weergegee word, is dit ekwivalent aan al die ander definisies of vorme soos omvat in die verskillende teoretiese strominge.

\subsection{Aktiewe drywing}

Aktiewe drywing word vir periodiese golfvorms (met periode $\mathrm{T}$ ) soos volg gedefinieer:

$$
P=\frac{1}{T} \int_{1}^{1+T} u(t) \cdot i(t) d t
$$

waar $u(t)$ die spanning- en $i(t)$ die stroomtydfunksies voorstel. Vergelyking (3) impliseer dat $P$ 'n tydgemiddeld van net to energie-oordrag na die las verteenwoordig en kan afgelei word uit vergelyking (4), waar $u(t)$ die energie per eenheidslading $\frac{\mathrm{d} w}{\mathrm{dt}}$ en $\mathrm{i}(\mathrm{t})$ die lading per cenheidstyd $\frac{\mathrm{dq}}{\mathrm{dt}}$ is.

$$
P=\frac{1}{T} \int_{1}^{1+1} \frac{d w}{d q} \cdot \frac{d q}{d t} d t=\frac{1}{T} \int_{1}^{1+1} d w
$$

$P$ is dus daardie hoeveelheid energie per tydseenheid wat aan die las oorgedra word en verteenwoordig die enigste gedeelte van die beladingsdrywing $S$ wat as nuttig vir drywingsoordrag beskou kan word.

\subsection{Beladingsdrywing}

Die term beladingsdrywing (pleks van skyndrying) is die eerste keer deur Enslin' voorgestel. Dit dui meer toepaslik op die hoeveelheid drywing waarmee 'n stelsel "belas" of "belaai" word. S kan ook gesien word as die potensiële vermoë van 'n stelsel of as die totale hoeveelheid drywing (hetsy aktief, reaktief ens.) wat in 'n stelsel teenwoordig is.

Beladingsdrywing word gedefinieer as die produk van die effektiewe waardes ( $U$ en 1 ) van die stroom en spanning of:

$$
\mathrm{S}=\mathrm{U} . \mathrm{I}
$$

waar $U=\left[\frac{1}{T} \int_{t}^{t+T} u^{2}(t) d t\right]^{t}$ en $I=\left[\frac{1}{T} \int_{t}^{t+r} i^{2}(t) d t\right]^{t}$

Beladingsdrywing kan dus beskou word as daardie hoeveelheid drywing wat aan die las oorgedra sou word, indien die las heeltemal resistief sou wees. Dit omvat dus die totale potensiële drywing in 'n stelsel teenwoordig, maar die potensiële drywing kan gewoonlik ontbind word in verskillende tipes drywing, waarvan slegs die aktiewe drywing $(P)$ bruikbare energie-oordrag lewer. 


\section{BUDEANU-DRYWINGSTEORIE}

Budeanu ${ }^{2}$ was die eerste om in 1927 ' $n$ algemene teorie van elektriese drywing vir nielineêre stelsels voor te stel. Sy teorie berus op 'n harmoniese analise van die stroom en spanning waaruit die verskillende ortogonale drywingskomponente bereken kan word. Gestel die stroom en spanning is periodies $\left(\right.$ met $\left.\mathrm{T}=2 \frac{\pi}{\omega}\right) \mathrm{en}$ :

$$
\begin{aligned}
& \mathrm{u}(\mathrm{t})=\sqrt{ } \sum_{\mathrm{n}} \mathrm{U}_{\mathrm{n}} \cos \left(\mathrm{n} \omega \mathrm{t}+\alpha_{\mathrm{n}}\right)+\mathrm{U}_{\mathrm{o}} \\
& \mathrm{i}(\mathrm{t})=\sqrt{ } 2 \sum_{\mathrm{m}} \mathrm{I}_{\mathrm{m}} \cos \left(\mathrm{m} \omega \mathrm{t}+\beta_{\mathrm{m}}\right)+\mathrm{I}_{\mathrm{o}}
\end{aligned}
$$

waar $\mathrm{n}$ die versameling spanningsharmonieke, $\mathrm{m}$ die stroomharmonieke, $\mathrm{U}_{\mathrm{n}}$ die effektiewe reële harmoniese spanningswaardes, $I_{m}$ die effektiewe harmoniese stroomwaardes en $\mathrm{U}_{\mathfrak{o}}$ en $\mathrm{I}_{\mathfrak{o}}$ die onderskeie gemiddelde waardes is. Dan is:

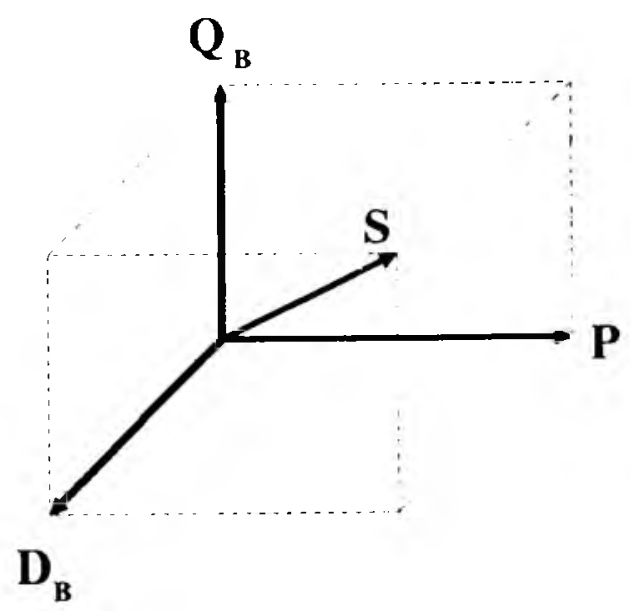

FIGUUR 1: Ortogonale drywingskomponente volgens Budeanu.

$$
\begin{gathered}
S=\left[\sum_{n} U_{n}^{2} \cdot \sum_{n 1} I_{m}^{2}\right]^{!} \\
\text {en } P=\sum_{j \in(m \cap n)} U_{j} I_{j} \cos \left(x_{j}-\beta_{j}\right)+U_{o} I_{o} .
\end{gathered}
$$

Budeanu ontbind $\mathrm{S}$ in drie ortogonale komponente (figuur 1) sodat:

$$
\mathrm{S}^{2}=\mathrm{P}^{2}+\mathrm{Q}_{\mathrm{B}}^{2}+\mathrm{D}_{\mathrm{B}}^{2} .
$$

Reaktiewe drywing $\left(Q_{B}\right)$ en vervormingsdrywing $\left(D_{B}\right)$ word verder voorgestel as:

$$
\begin{gathered}
\mathrm{Q}_{\mathrm{B}}=\sum_{\mathrm{j} \in(\mathrm{m} \cap \mathrm{n})} \mathrm{U}_{\mathrm{j}} \mathrm{I}_{\mathrm{j}} \sin \left(\alpha_{\mathrm{j}}-\beta_{\mathrm{j}}\right) \\
\text { en } \mathrm{D}_{\mathrm{B}}^{2}=\mathrm{S}^{2}-\mathrm{P}^{2}-\mathrm{Q}_{\mathrm{B}}^{2}
\end{gathered}
$$

Vergelyking (7) en (8) vir $\mathrm{S}$ en $\mathrm{P}$ is ekwivalent aan die algemene definisies (5) en (3), terwyl $\mathrm{Q}_{\mathrm{B}}$ die somtotaal van die sinusgedeeltes van die binneprodukte tussen spanning- en stroomharmonieke is. $D_{B}$ is die vektorverskil tussen $S, P$ en $Q_{B}$ en verteenwoordig die drywing as gevolg van die stroomharmonieke by frekwensies wat nie in die spanning teenwoordig is nie.

Nowomiejski ${ }^{3}$ toon in 1981 hoe Budeanu se drywingsmodel uitgebrei kan word na 'n kontinue of spektrale frekwensievlak. Hy gebruik die Hilberttransform om aan te toon dat aktiewe drywing verteenwoordig word deur die integraal van die reële of kovlak van die kruisspektraaldigtheidsfunksie (dit wil sê die produk tussen die Fouriertransforms van die spanning en stroom) en dat die reaktiewe drywing verkry kan word as die integraal van dic imaginêre of kwadratuurspektrum van hierdie kruisspektraaldigtheidsfunksie.

Hoewel Budeanu se model, en later ook Nowomiejski se veralgemening hiervan, algemeen aanvaar is, blyk die definisie van die reaktiewe drywing $\left(\mathrm{Q}_{\mathrm{B}}\right)$ slegs 'n wiskundige formulering te wees. Czarnecki toon $\operatorname{aan}^{4}$ dat die somtotaal $Q_{B}$ nie 'n praktiese waarde is nie, aangesien die kompensasie van $Q_{B}$ nie noodwendig tol die maksimum arbeidsfaktor in 'n stelsel lei nie.

Dit blyk verder dat $D_{\mathrm{B}}$ gekies is om die vektorsom na $S$ toe vol te maak en dat dit geen besondere kennis oor die vervorming in die stelsel (as gevolg van byvoorbeeld nielineariteite) verskaf nie.

\section{ELEKTRIESE DRYWING IN DIE TYDVLAK}

Om drywingsanalise effektief te kan benut, is dit nodig om die verskillende drywingskomponente vinnig en akkuraat te kan bepaal. Harmoniese en spektraalanalise behels gewoonlik ' $n$ frekwensietransform wat langer berekeningstyd impliseer. Dit is om hierdie rede dat 'n skool ontstaan het wat die tyddomeinanalise voorstaan, waaronder Fryze ${ }^{5}$ (1932) en later ook Enslin'1 (1988).

Fryze $^{5}$ ontbind die lasstroom in twee ortogonale komponente, naamlik 'n aktiewe komponent $i_{a}(t)$ (wat netto energieoordrag lewer) en 'n fiktiewe komponent $i_{r}(t)$ wat geen bydrae tot energie-oordrag lewer nie.

Indien die fiktiewe stroom ideaal deur 'n kompensator voorsien word (figuur 2), sal die bron slegs aktiewe stroom teen 'n eenheidsarbeidsfaktor lewer. Die aktiewe stroomkomponent moet dieselfde golfvorm as die spanning of dryffunksie $u(t)$ hê sodat:

$$
\begin{aligned}
i_{\mathrm{a}}(\mathrm{t}) & =\mathrm{G}_{\mathrm{c}} \cdot \mathrm{u}(\mathrm{t}) \\
\text { waar } \mathrm{G}_{\mathrm{c}}=\frac{\mathrm{P}}{\mathrm{U}^{2}}= & \frac{\frac{1}{\mathrm{t}} \int_{\mathrm{t}}^{t+\mathrm{T}} \mathrm{u}(\mathrm{t}) \cdot \mathrm{i}(\mathrm{t}) \mathrm{dt}}{\frac{1}{\mathrm{~T}} \int_{\mathrm{t}}^{1+\mathrm{T}} \mathrm{u}^{2}(\mathrm{t}) \mathrm{dt}}
\end{aligned}
$$

Die fiktiewe stroomkompensator (soos in figuur 2 getoon) is ' $n$ ak tiewe stelsel wat $i_{i}(t)$ dinamies kan genereer. So 'n kompensator is duurder as passiewe elemente (bv. 'n kapasitorbank) en word gewoonlik slegs vir die kompensasie van vinnig variërende stroomverskynsels gebruik. Indien die fiktiewe stroom onder andere in 'n reaktiewe stroomkomponent verdeel sou word, sou hierdie reaktiewe drywing (en dus reaktiewe stroom), ideaal deur passiewe energiestoorelemente (bv. 'n kapasitorbank) voorsien kan word. So 'n konfigurasie word in figuur 3 getoon. 


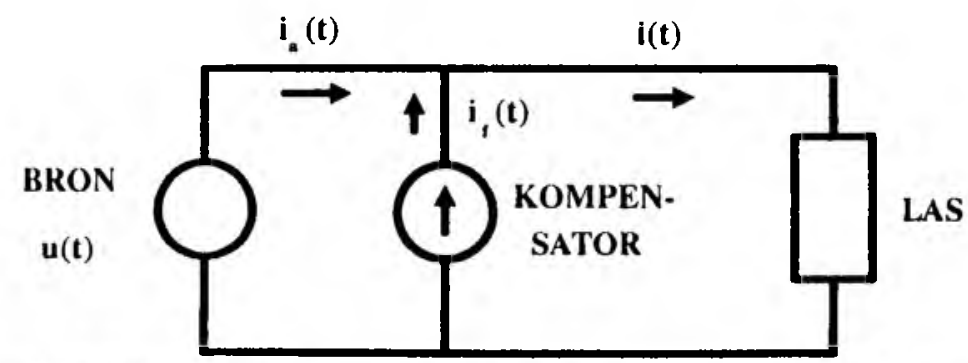

FIGUUR 2: Stroomkomponente en kompensasie volgens Fryze.

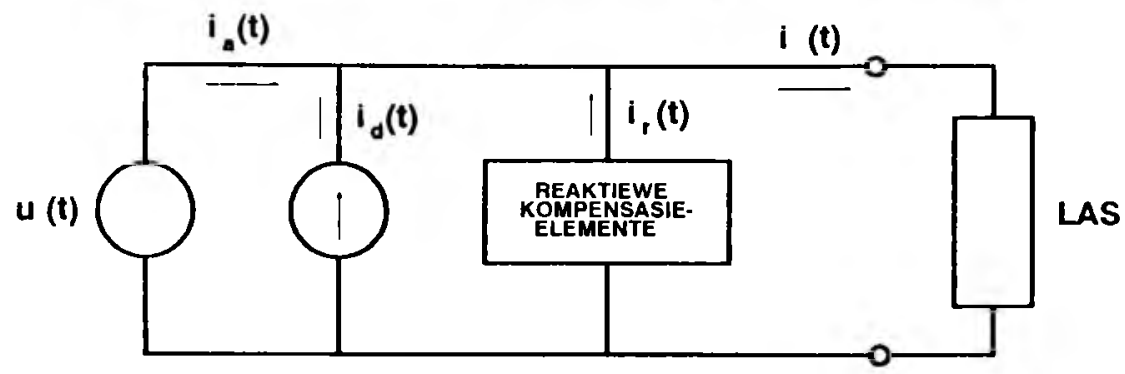

FIGUUR 3: Kompensasieskema volgens Enstin.'

Enslin' het gepoog om drywing en stroomkomponente op hierdie manier in die tyddomein te ontbind. 'n Aktiewe $\left(i_{i l}(t)\right)$, reaktiewe $\left(i_{r}(t)\right)$ en deaktiewe $\left(i_{d}(t)\right)$ stroomkomponent word gedefinieer met behulp van die onderlinge drywingskomponente:

$$
\begin{aligned}
\mathrm{P} & =\mathrm{R}_{\mathrm{ut}}(0) \\
\mathrm{Q}_{\mathrm{B}} & =\left|\hat{\mathrm{R}}_{\mathrm{ui}}^{2}(\tau)-\mathrm{R}_{\mathrm{ui}}^{2}(0)\right|^{\frac{1}{2}} \\
\mathrm{D}_{\mathrm{E}}^{2} & =\mathrm{S}^{2}-\mathrm{P}^{2}-\mathrm{Q}_{\mathrm{E}}^{2}
\end{aligned}
$$

waar $R_{u i}(\tau)$ die kruiskorrelasie tussen die stroom en spanning is met

$$
\mathrm{R}_{\mathrm{ul}}(\tau)=\frac{1}{\mathrm{~T}} \int_{\mathrm{l}}^{\mathrm{t}+\mathrm{T}} \mathrm{u}(\mathrm{t}) \cdot \mathrm{i}(\mathrm{t}-\tau) \mathrm{dt}
$$

Aktiewe drywing volgens vergelyking (14) is dieselfde as die algemene definisie van vergelyking (3).

$Q_{E}$ kan volgens Enslin bepaal word deur die aktiewe drywing van die maksimum gekorreleerde waarde $\hat{\mathrm{R}}_{\mathrm{ui}}(\tau)$ af te trek, waar $\hat{\mathrm{R}}_{\mathrm{ui}}(\tau)$ daardie hoeveelheid gekorreleerde drywing sou wees as gevolg van die faseverskil tussen stroom en spanning, terwyl $D_{k}$ die residuele drywing as gevolg van nielineariteite blyk te wees. Vir $\mathrm{Q}_{\mathrm{E}}$ om die maksimum hoeveelheid drywing te wees, wat na kompensasie met lineêre energiestoorelemente die maksimum arbeidsfaktor sal lewer, moet daar 'n $\mathrm{Q}_{\mathrm{E}}$ gevind word wat afhanklik is van al die frekwensies wat in die dryffunksie $u(t)$ voorkom.

Daar is egter getoon ${ }^{6}$ dat die drywing $Q_{E}$ arbitrêr en onafhanklik is van die frekwensies wat in die dryffunksie voorkom, sodat $\mathrm{Q}_{\mathrm{E}}$ nie noodwendig maksimum kompensasie tot gevolg sal hê nie. Hoewel die vergelyking vir $Q_{E}$ wel die optimum kompensasie by 'n enkelharmoniese $u(t)$ sal lewer, is daar verder aangetoon ${ }^{6}$ dat in so 'n geval die korrelasiefunksies van (14) en (15) deur twee integrale vervang kan word (ongeag die harmonieke in $\mathrm{i}(\mathrm{t})$ teenwoordig) wat moontlik 'n vermindering in berekeningstyd tot gevolg kan hê.

Alhoewel aktiewe en beladingsdrywing in die tyddomein bereken kan word (vergelykings (3) en (5)), is totale reaktiewe drywing wat vir passief kompenseerbare drywingsossillasies verantwoordelik is, in dic algemeen frekwensie-athanklik, sodat 'n volledige lasinterpretasie van $Q$ nie in die tyddomein bereken kan word nie $^{0}$ en daar kan dus gesien word dat, behalwe vir $P$ en $\mathrm{S}$, dit nie noodwendig sinvol is om drywing vir optimum kompensasie volledig in die tyddomein te karakteriseer nie.

\section{6. 'N NUWE DRYWINGSTEORIE (VOLGENS CZARNECKI)}

Czarnecki se teorie ${ }^{7}$ behels die ontbinding van die lasstroom in 'n aantal stroomkomponente en hulle verwante drywingskomponente (figuur 4). Hierdie teorie is 'n verbetering op vorige teorieë, omdat daar nie net mér gesê word oor die oorsake van die verskillende komponente nie, maar daar ook beter insig verkry word in optimale kompensasie en verwante arbeidsfaktore.

Gestel die stroom en spanning is periodies (met $\mathrm{T}=2 \frac{\pi}{\omega}$ en $\mathrm{n}$ die versameling spanningsharmonieke en $m$ die versameling stroomharmonieke), dan is:

$$
\begin{aligned}
u(t) & =、 2 \operatorname{Re} \sum_{n} U_{n} e^{i n e n t} \\
\text { en } i(t) & =、 2 \operatorname{Re} \sum_{m} I_{m} e^{j m u t}
\end{aligned}
$$

waar $U_{n}$ en $I_{n}$ die komplekse harmoniese effektiewe spanning en stroomwaardes is.

Die komplekse admittansiefunksie word by die harmonieke van die spanning gedefinieer as:

$$
\Lambda_{\mathrm{n}}=\frac{\mathrm{I}_{\mathrm{n}}}{\mathrm{U}_{\mathrm{n}}}=\gamma_{\mathrm{n}}+\mathrm{j} \beta_{\mathrm{n}}
$$

Aktiewe stroom het dieselfde betekenis as by ander teorieë (sien ook vergelyking (12)) sodat:

$$
\mathrm{i}_{\mathrm{in}}(\mathrm{t})=\mathrm{G}_{\mathrm{c}} \cdot \mathrm{u}(\mathrm{t})=\frac{\mathrm{P}}{\mathrm{U}^{2}} \cdot \mathrm{u}(\mathrm{t})=v 2 \operatorname{Re} \sum_{n} \mathrm{G}_{\mathrm{c}} \mathrm{U}_{n} \mathrm{e}^{\mathrm{j} \mathrm{n} / \mathrm{n}}
$$




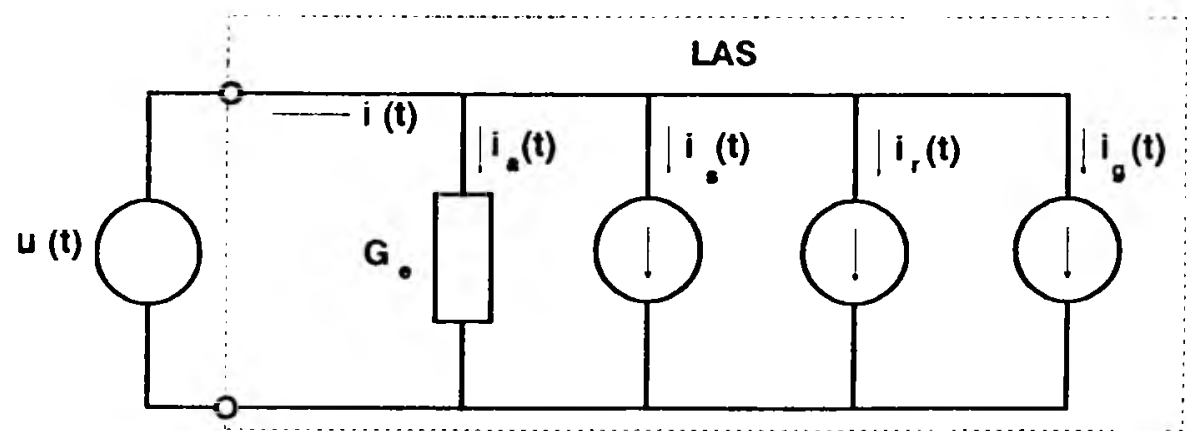

FIGUUR 4: Lasstroomkomponente volgens Cannecki:

$i_{i l}(t)$ - aktiewe stroom

$i_{s}(t)$ - verstrooide stroom

$i_{r}(t)$ - reaktiewe stroom

$\mathrm{i}_{\mathrm{g}}(\mathrm{t})$ - nicharmoniese of gegenereerde stroom.

Die aktiewe drywing $\mathrm{P}$ kan ook bereken word as:

$$
\mathrm{P}=\mathrm{U} \mathrm{I}_{\mathrm{i}} \text {. }
$$

waar $\mathrm{I}_{\mathrm{a}}$ die effektiewe waarde van die stroomkomponent $i_{a}(t)$ is, net soos wat $I$ as die effek tiewe waarde van $i(t)$ in (5) bereken is.

Reaktiewe stroom word geassosieer met die komplekse gedeeltes van die lasadmittansie $\left(\beta_{n}\right.$ in $\left.\Lambda_{n}\right)$ en is die totale stroom wat verantwoordelik is vir drywingsossillasies by die harmonieke van $u(t)$. Reaktiewe stroom kan in totaal deur passiewe reaktiewe elemente (dit wil sê induktore, kapasitore of samestellings hiervan) gekompenseer word, sodat:

$$
\mathrm{i}_{\mathrm{r}}(\mathrm{t})=\sqrt{ } \operatorname{Re} \sum_{\mathrm{n}} \mathrm{j} \beta_{\mathrm{n}} \mathrm{U}_{\mathrm{n}} \mathrm{e}^{\mathrm{j} n \mathrm{n} \cdot \mathrm{t}}
$$

Die reaktiewe drywingskomponent word bereken as:

$$
\mathrm{Q}_{\mathrm{r}}=\mathrm{UI}_{\mathrm{r}}
$$

waar $I_{r}$ die effektiewe waarde van $i_{r}(t)$ is.

Die gegenereerde of nieharmoniese stroom $\left(\mathrm{i}_{\mathrm{g}}(\mathrm{t})\right)$ kom slegs voor in nielineêre stelsels en is dié komponent wat in die las ontstaan by harmonieke wat nie in die dryffunksie $u(t)$ voorkom nie, sodat:

$$
i_{g}(t)=\sqrt{2} \operatorname{Re} \sum_{k \notin n} I_{k} e^{j k(\cdot)}
$$

Weereens kan die nieharmoniese drywingskomponent bereken word deur eers die effektiewe waarde $\mathrm{I}_{\mathrm{g}}$ van die nieharmoniese stroom $I_{g}(t)$ te bereken en dit met die effektiewe spanning $U$ te vermenigvuldig of:

$$
\mathrm{D}_{\mathrm{g}}=\mathrm{UI}_{\mathrm{g}}
$$

Alhoewel $i_{\mathrm{g}}(\mathrm{t})$ ook vir drywingsossillasies verantwoordelik kan wees, kom dit nie voor by dieselfde frekwensies as dié in $\mathrm{u}(\mathrm{t})$ nie, sodat dit nie deur passiewe reaktiewe komponente gekompenseer kan word nie.

Die effek van die laaste komponent, naamlik verstrooide stroom $i_{s}(t)$, word eers deur 'n voorbeeld getoon: in figuur 5 word 'n lineêre stroombaan getoon waar $\mathrm{u}(\mathrm{t})$ uit twee harmonieke $\mathrm{U}_{1}=\mathrm{IV}$ en $\mathrm{U}_{3}=\frac{1}{3} \mathrm{~V}$ (by $\omega_{1}=1$ rad. $s^{-1}$ en $\omega_{3}=3$ rad.s ${ }^{1}$ ) bestaan. Verder is:

$$
\begin{aligned}
& \mathbf{S}=\mathrm{U} . \mathrm{I}=\sqrt{\sum_{\mathrm{n}} \overline{\mathrm{U}}_{\mathrm{n}}^{2}} \cdot \sqrt{\sum_{\mathrm{n}} \overline{\mathrm{I}}_{\mathrm{n}}^{2}} \\
& =\sqrt{\sum_{n} \bar{U}_{n}^{2}} \cdot \sqrt{\sum_{n} \bar{\Lambda}_{n}^{2} \cdot \bar{U}_{n}^{2}}=\sqrt{\frac{600}{960}} V A
\end{aligned}
$$

$\operatorname{met} \bar{\Lambda}_{n}=\frac{R-j \omega_{n} L}{R^{2}+\omega_{n}^{2} L^{2}}$

Terwyl:

$\sqrt{\mathrm{P}^{2}+\mathrm{Q}_{\mathrm{r}}^{2}}=\sqrt{\left(\sum_{\mathrm{n}} \gamma_{\mathrm{n}} \overline{\mathrm{U}}_{\mathrm{n}}^{2}\right)^{2}+\left(\mathrm{U} \cdot \sum_{\mathrm{n}} \beta_{\mathrm{n}}^{2} \overline{\mathrm{U}}_{\mathrm{n}}^{2}\right)^{2}}$

$=\sqrt{\overline{984}} \mathrm{VA} \quad(\mathrm{B})$

Die verskil in waardes tussen (A) en (B) is die gevolg van verstrooide stroom. Dit kom voor as gevolg van die onbalans van die harmoniese admittansies om die ekwivalente konduktansie $G_{\mathbf{c}}$. Die feit dat by elke n-de harmoniek, $\gamma_{n}$ afwyk van $G_{c}$, gee aanleiding tot 'n stroomkomponent wat nie netto energie-oordrag lewer nie, aangesien energie-oordrag slegs plaasvind in 'n konduktansie $\mathrm{G}_{\mathrm{c}}$ (wat konstant is vir alle frekwensies; figuur 4). Hierdie komponent is die verstrooide stroom $i_{s}(t)$ en kan uitgedruk word as:

$$
i_{s}(t)=\sqrt{2} \operatorname{Re} \sum_{n}\left(\gamma_{n}-G_{c}\right) U_{n} e^{j n c o t}
$$

$u(t)$

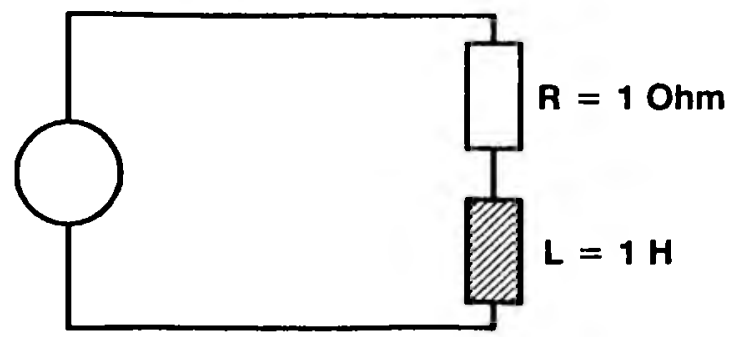

FIGUUR 5: Linềre stroombaan waar die spanning uit twee harmonieke bestaan.

Indien al die reële gedeeltes van $\Lambda_{n}$ dieselfde waarde sou gehad het, sou $i_{g}(t)=0$ gewees het. (Verstrooide stroom en drywing kom ook tipies by frekwensie-afhanklike weerstande voor.) Hierdie stroomkomponent is nie kompenseerbaar met reaktiewe elemente nie en verminder die maksimum reaktiefkompenseerbare arbeidsfaktor in 'n lineêre stelsel na:

$$
\gamma_{\text {maks }}=\frac{P}{S}=\frac{1}{\sqrt{1+\left[\frac{I_{s}}{I_{a}}\right]^{2}}}
$$

waar $I_{\mathrm{s}}$ en $I_{\mathrm{a}}$ dic effek tiewe waardes van onderskeidelik die verstrooide en aktiewe stroom is.

Indien $I_{r}$ en $I_{g}$ verder die effektiewe waardes van die 
reaktiewe en gegencreerde stroom sou voorstel, word die totale beladingsdrywing gedefinieer as:

$$
\begin{aligned}
& S^{2}=U^{2}\left(I_{a}^{2}+I_{r}^{2}+I_{r}^{2}+I_{g}^{2}\right) \\
& \text { of } S^{2}=P^{2}+D_{s}^{2}+Q_{r}^{2}+D_{g}^{2}
\end{aligned}
$$

met $P$ die ak tiewe, $D_{s}$ die verstrooide, $Q_{r}$ die reaktiewe en $D_{g}$ die nieharmoniese drywingskomponente. $Q_{r}$ is ten volle met reaktiewe komponente kompenseerbaar en verskil van $\mathrm{Q}_{\mathrm{B}}$ (soos deur Budeanu voorgestel) deurdat dit 'n vektoriële effek tiewewaardeproduk U. Ir is, terwyl $Q_{B}$ die skalaarsom van al die onderling harmoniese reak tiewe drywings aandui en geen besondere fisiese betekenis het nie.

Die ortogonale drywingskomponente van vergelyking (29) besit dus almal betekenis wat herlei kan word na relevante arbeidsfaktore (soos byvoorbeeld dié van vergelyking (27)) of spesifieke oorsake (dit wil sê nielineariteite of harmoniese wanbalans) en is 'n definitiewe verbetering op die gebied van algemene drywingsteorie en drywingsanalise.

\section{SAMEVATTING}

Die strominge in drywingsteorie vanaf die klassieke, dié van Budeanu, dié in die tyddomein en dié van Czarnecki, is getoon.

Daar is getoon dat deur die teorieë van Budeanu en Nowomiejski daar nie 'n praktiese bydrae tot die teg- nologie van korrekte kompensasie van vervorming gemaak is nie.

Die tekortkominge van die tydvlakbeskouing en in besonder dié van Enslin is bespreek, terwyl daar laastens na die teorie van Czarnecki verwys is wat drywingskomponente in so ' $n$ mate ontbind dat dit onder andere sinvolle hoeveelhede vir reaktiewe kompensasie voorstel en bydra tot die begrip van dic oorsprong van die verskillende tipes drywing.

\section{LITERATULRVERWYSINGS}

I. Enslin, J. H. R. (1988). Determination and Dynamic Compensation of Fictitious Power in Flectric Power Systems, D.Ing. Verhandeling. Randse Afrikatanse Universiteit.

2. Budeanu, C. I. (1927). Puissances reactives et fictives, Ins/y/ut Romain de l'Energie, Bucharest. Romennie.

3. Nowomicjski, Z. (1981). Generalized theory of electrical power. Arch.f. Elektrotech., vol. 63, 177-182.

4. Czarnecki, L. S. (1987). What is Wrong with the Budeanu Concept of Reactive and Distortion Power and Why it Should be Abandoned, IEEE Trans. Instrum. and Meas., vol. IM-36 no. 3, 834-837.

5. Fryze, S. (1932). Wirk-, Blind- und Scheinleistung in elektrische Stromkreisen mit nichtsinusoidalformigen Verlauf von Strom, und Spannung, ETZ, vol. 53, no. 25, 596-599, 625-627, 700-702.

6. De Beer, A. S. (1990). Determination of Power Components in Nonlinear Electrical Networks, M.Ing. V'rhandeling, Randse Afrikaanse Universiteit.

7. Czarnecki, L. S. (1983). An orthogonal decomposition of the current of non-sinusoidal voltage source applied to nonlinear loads, Int. J. Circuit Theory Appl., Vol. II, 235-239. 